\title{
Harnessing the ngs-based rna sequencing technology for genetic resource identification and applications in bivalve shellfish aquaculture
}

Volume 4 Issue I - 2016

\begin{abstract}
Abbreviations: FAO, Food and Agriculture Organization of the United Nations; OGC, Oyster Genome Consortium; NGS, NextGeneration Sequencing; SSH, Suppression Subtractive Hybridization; SSR, Simple Sequence Repeat
\end{abstract}

\section{Editorial}

Aquaculture is the fastest growing animal-food producing sector and promises an important role in meeting the food-demand of the global population. Aquaculture supports the livelihoods of $10-12 \%$ of world's population with sustainable economic opportunities. The sector has generated global recognition and is included in FAO's (Food and Agriculture Organization of the United Nations) strategic objectives of alleviating malnutrition and hunger, ushering an era of food security. There is a strong undercurrent of entreprenrship activities in the sector, which has satiated the demand for fish globally, and has been efficient in reducing rural poverty and community resilience to climate change crisis. In 2010, the global fish production by capture and aquaculture was 148 million tons and in 2012, while global capture fishery production was stable, global aquaculture production showed a growth of more than 90 million tonnes. ${ }^{1}$ The world bivalve mollusc production that represents $10 \%$ of total world aquaculture production has increased substantially to about 14.6 million tons in 2010. The major share of bivalve production with 10.35 million tons in 2010 comes from China, followed by Japan (819,131 tons), the USA (676,755 tons), and the Republic of Korea (418,608 tons).

With a growing incentive in bivalve aquaculture and fishery production, technological developments such as polyploidy production, ongoing selection and breeding programs have flourished. ${ }^{2}$ Scallops, oysters, clams and mussels are among the important bivalve species in global aquaculture. In the bivalve trade, scallops are the most important species with $46 \%$ of value, closely followed by mussels (26\%). Besides aquaculture values, bivalves are organisms of choice for environmental monitoring studies as they are adapted to a variety of environments, and due to their filter feeding, can accumulate xenobiotic compounds.

In response to the importance of bivalves to global aquaculture production and environmental monitoring studies, bivalve genomics made a head-start with the Oyster Genome Consortium (OGC), comprising of 70 individuals from 11 countries. $^{3}$ Under this community genome initiative, the Pacific oyster (Crassostrea gigas) was a candidate for genome sequencing that provided unparalled resources for a broad range of studies on evolution and environmental sustainability. The study was one of the initial attempts to harness next-generation sequencing (NGS) technology for understanding the complexity of bivalve genomes. Parallel to the use of NGS in bivalve genomics, the high-throughput, NGS of RNA, called RNA-seq has been useful in rapid dissemination of important genomic information in bivalves, especially the identification of transcripts for adaptation

\section{Bharat Bhusan Patnaik, Yong Seok Lee \\ Bioinformatics Laboratory, Department of Life Science and Biotechnology, Soonchunhyang University, Asan City, South Korea}

Correspondence: Bharat Bhusan Patnaik, Department of Life Science and Biotechnology, Soonchunhyang University, Asan City, South Korea-336745 \& Trident School of Biotech Sciences, Trident Academy of Creative Technology (TACT), Bhubaneswar-751 024, Odisha, India, Email yslee@sch.ac.kr(Y.S.L)

Received: December 03, 2015 | Published: January 08, 2016

and reproduction with the development of genetic markers. RNA-seq has been an attractive option for studying non-model organisms as they are more reliable and cheaper than building genomes.

The NGS platforms for whole-transcriptome and tissue-specific transcriptome characterization of bivalve species include the 454/Roche and Solexa/Illumina. Most NGS de novo transcriptome sequencing projects in bivalves have used the 454/Roche pyrosequencing system. Roche's 454 GS-FLX platform provides a longer read size with deep sequencing coverage and has been widely used for de novo transcriptome sequencing of bivalves such as Bathymodiolus et al. ${ }^{4}$ Ruditapes . ${ }^{5}$ Mytilus. ${ }^{6}$ Sinonovacula. ${ }^{7}$ and Crassostrea. ${ }^{8}$ Lately, Illumina sequencing technology (short, paired-end reads) has been the preferred choice due to algorithmic advances, highly replicable, and cost-efficient process for transcriptome characterization. In addition, it is a superior method for the identification of differentially expressed transcripts. The bivalve species for which Illumina facility was successfully used for transcriptome characterization includes Haliotis. ${ }^{9}$ Chlamys. ${ }^{10}$ Pecten. ${ }^{11}$ and Crassostrea. ${ }^{12}$ Notwithstanding the NGS platform used, genomic resources in the form of a rich repertoire of genes related to innate immunity, digestion, sex-determination, reproduction and environmental stress have been divulged from the analysis. We have also conducted the transcriptome characterization of an endangered freshwater pearl bivalve, Cristaria plicata, and have discovered a rich set of immune and reproduction-related genes. With this, we have characterized the simple sequence repeat (SSR) markers that would be relevant for genetic characterization and conservation studies.

\section{Conclusion}

Although initial transcriptomic analysis in bivalves were based on technologies such as cDNA libraries, suppression subtractive hybridization libraries (SSH) and microarrays, RNA-seq provides highthroughput, unparalled and unbiased gene expression information. The NGS platforms have provided rich resources for many economic 
bivalve species especially with reference to expression of genes related to vital metabolic, cellular, and immune processes. This has added to the meaningful genetic resource data stored in databases to be utilized as a public information platform for exploitation in functional analysis. In the near future, we can expect an increase in transcriptome sequencing that will provide clues for their potential applications in biomonitoring of environmental contaminants and further improve their accessibility for aquaculture production.

\section{Acknowledgements}

This study is supported by the grant entitled "The Genetic and Genomic Evaluation of Indigenous Biological Resources" funded by the National Institute of Biological Resources (NIBR201503202) to the second author.

\section{Conflicts of interest}

None.

\section{References}

1. FAO The state of world fisheries and aquaculture. Opportunities and challenges. Food and Agriculture organization of the United Nations, Rome, Italy. 2014

2. Zheng H, Zhang G, Liu X, Zhang F, Guo X Different responses to selection in two stocks of the bay scallop, Argopectenirradians Lamarck (1819). Journal of Experimental Marine Biology and Ecology. 2004;313(2):213-223.

3. Hedgecock D, Gaffney PM, Goulletquer P, et al. The case for sequencing the Pacific oyster genome. Journal of Shellfish Research. 2005;24 (2):429-441.
4. Bettencourt R, Pinheiro M, Egas C, et al. High-throughput sequencing and analysis of the gill tissue transcriptome from the deep-sea hydrodermal vent mussel Bathymodiolus azoricus. BMC Genomics. $2010 ; 1: 362$

5. Milan M, Coppe A, Reinhardt R, et al. Transcriptome sequencing and microarray development for the Manila clam, Ruditapes philippinarum: genomic tools for environmental monitoring. BMC Genomics. 2011;12(1):234.

6. Philipp EER, Kraemer L, Melzner F, et al. Massively parallel RNA sequencing identifies a complex immune gene repertoire in the lophotrochozoan Mytilus edulis. PLoS ONE. 2012;7(3): e33091.

7. Niu D, Wang L, Sun F, et al.Development of molecular resources for an intertidal clam, Sinonovacula constricta, using 454 transcriptome sequencing. PLoS ONE. 2013;8(7):e67456.

8. Tong Y, Zhang Y, Huang J, et al. Transcriptomics analysis of Crassostrea hongkongensis for the discovery of reproduction-related genes. PLoS ONE. 2015;10(8) e 0134280 .

9. Franchini $\mathrm{P}$, van der Merwe $\mathrm{M}$, Roodt-Wilding $\mathrm{R}$ Transcriptome characterization of the South African abalone Haliotismidae using sequencing-by-synthesis. BMC Res Notes. 2011;4: 59.

10. Shi M, Lin Y, Xu G, Xie L, et al. Characterization of the Zhikong scallop (Chlamys farreri) mantle transcriptome and identification of biomineralization-related genes. Mar Biotechnol. 2013;15(6):706-715.

11. Pauletto M, Milan M, Moreira R, et al. Deep transcriptome sequencing of Pecten maximus hemocytes: A genomic resource for bivalve immunology. Fish Shellfish Immunol. 2014;7(1):154-165.

12. Zhang L, Li L, Zhu Y, et al. Transcriptome analysis reveals a rich gene set related to innate immunity in the Eastern Oyster (Crassostrea virginica). Mar Biotechnol. 2014;16(1):17-33. 